REVISTA CHILENA DE LITERATURA

Noviembre 2015, Número 91, 35-50

\title{
SUBVERSIÓN Y ESPECTÁCULO: LA ANTIPOESÍA DE NICANOR PARRA
}

\author{
Leonidas Morales Toro \\ Universidad de Chile \\ lmoralest@vtr.net
}

\section{RESUMEN / ABSTRACT}

El artículo propone, primero, considerar la obra de Parra posterior a los Sermones y prédicas del Cristo de Elqui, es decir, desde la década de 1980 en adelante, como posmoderna, y, segundo, plantea la tesis de que esta obra posmoderna se deja aprehender intelectivamente desde el concepto de "pastiche" (Jameson) como imitación de sí mismo.

El desarrollo de la argumentación crítica pone en juego diversos planos de la obra: signos, estructuras discursivas e imágenes visuales.

Palabras Clave: modernismo, posmoderno, pastiche, imitación, imagen visual.

This article proposes to consider Nicanor Parra's poetic work produced after Sermones y prédicas del Cristo de Elqui, that is from the 1980s onwards, as postmodern. Following this consideration, this postmodern work can be intellectively apprehended from Jameson's concept of "pastiche" as imitation of itself. The development of the critical argumentation takes into account diverse aspects of Parra's work, such as signs, discursive structures, and visual images.

KEY WORDS: modernism, postmodern, pastiche, imitation, visual image. 
Este ensayo tiene en la mira la antipoesía posmoderna de Nicanor Parra: la posterior a los libros Sermones y prédicas del Cristo de Elqui ${ }^{1}$ y Nuevos sermones y prédicas del Cristo de Elqui ${ }^{2}$ (1977 y 1979). En otras palabras, la publicada desde la década de 1980 en adelante. El tema de una fase "posmoderna" de la antipoesía, cuya condición de posibilidad sería precisamente el cierre (su cumplimiento) de la fase anterior, la antimodernista, fue postulado (pero no explorado), como también sus encuadres cronológicos, en mi último ensayo sobre Parra ${ }^{3}$. Como insistiré más adelante, se trata (y más allá de sus apariencias) de una poesía cuyo estatuto estético es muy distinto al de la poesía anterior, diferencia que si bien se manifiesta en planos diversos, están todos correlacionados. Pero para entrar en este tema específico propuesto quiero pasar previamente, y sin detenerme en ninguno de ellos, por dos dominios del saber sobre la poesía de Parra, desiguales desde el punto de vista de su constitución y de su recepción. El primero es un saber ya establecido y más o menos generalizado dentro de la comunidad crítica chilena (y extranjera). El segundo en cambio es el de un saber menos codificado, más abierto críticamente, cuando no ausente por completo, pero de formulación indispensable para abordar la cuestión de las diferencias entre la poesía anterior y la posterior a los Sermones.

El primero: nadie duda hoy, entre los críticos, de cuál sea el lugar que ocupa Nicanor Parra en la poesía chilena contemporánea: sin duda, el de ser autor de una propuesta poética de efectos innovadores duraderos. Desde la segunda mitad de la década de 1940, un nuevo poema, el de Parra, comienza a abrirse paso en un diálogo contestatario, o mejor, subversivo, frente al tipo de poesía entonces dominante en Chile: la de Huidobro, Neruda, De Rokha, cuyos modelos de escritura eran todos de origen vanguardista. Una poesía pues, la de Parra, "antimodernista". El diálogo con esos modelos se da en niveles distintos pero de sentido convergente: en el plano del sujeto de la enunciación, en el del tipo de lenguaje, en el de la estructura del poema. Hoy podemos ver con especial claridad la naturaleza del giro que representaba

Santiago, Galería Época, 1977.

Valparaíso, Ediciones Ganymedes, 1979.

"Nicanor Parra: el proyecto antipoético". Anales de Literatura Chilena 17, junio de 2012, pp. 147-167. 
la propuesta de Parra dentro de la poesía chilena (y en general en la poesía en lengua española). Un giro cuyo verdadero sentido no podía ser visible en un primer momento. Hoy nos resulta evidente: situando toda poesía en el contexto de condiciones histórica a las que siempre responde de una u otra manera, la de Parra apuntaba en la dirección hacia la que la modernidad cultural y el capitalismo comenzaron a moverse después de la segunda guerra mundial, y que, desde la década de 1980, ha dejado de ser una dirección para constituirse en nuestro domicilio: la posmodernidad cultural como efecto de la globalización de la mercancía y sus discursos. En Chile, la posmodernidad y la globalización tienen, desde el punto de vista social, político, cultural, un origen inmediato traumático: fueron impuestos, sin transición, por la dictadura militar.

La propuesta de Parra, la de su antipoesía, aparece introduciendo otra idea de sujeto, otra clase de lenguaje, otra estructura de poema, a las que se suma un humor y una ironía de otra especie, que, en conjunto, negaba desde sus bases, y de un modo corrosivo, los modelos poéticos vigentes en Chile por lo menos desde la década de 1930. Si bien, como dije en aquel ensayo, Parra venía escribiendo el nuevo tipo de poesía desde la década de 1940, su entrada reconocida, "oficial", en el escenario de la poesía chilena y su recepción, y junto con ella, la instalación provocadora de su nombre, "antipoesía", se produce en 1954 con la publicación del libro Poemas y antipoemas. Un libro éste, como Altazor de Huidobro o las Residencias de Neruda, de rango a su modo fundacional, hoy casi mítico, en la historia de la poesía chilena contemporánea. A ese libro inaugural de Parra, el mismo que hoy cumple 60 años de su publicación (mientras su autor cumplirá cien) ${ }^{4}$, le siguieron desde luego muchos otros. La copiosa producción de Parra ha sido recogida recientemente en dos tomos con el título de Obras completas. Los dos tomos aparecieron en fechas diferidas publicados por la editorial Galaxia Gutenberg, de Barcelona 5 .

El segundo dominio de saber, más problemático, menos unánime, se refiere a la antipoesía posmoderna, cuya delimitación cronológica y textual quedó hecha al comienzo de este ensayo. En mi último ensayo sobre Parra, ya

4 Este ensayo comencé a escribirlo en el 2014, año justamente de ambos acontecimientos. Vol. I: Nicanor Parra, Obras completas \& algo + (1935-1972). Barcelona, Galaxia Gutenberg Círculo de Lectores, 2006. Vol. II: Nicanor Parra, Obras completas \& algo + (1975-2006). Barcelona, Galaxia Gutenberg Círculo de Lectores, 2011. 
citado, formulé justamente la tesis de que, a partir de Poemas y antipoemas, la poesía de Parra progresa, se despliega, configurando el perfil de lo que con propiedad podemos llamar un proyecto, en el sentido de una "aventura" poética de movimientos estratégicos. Lo cual supone que el lector, al seguir el movimiento de la antipoesía a través del tiempo (de la sucesión de sus libros), necesariamente descubre en ella la estructura de ese proyecto, es decir, sus encuadres, etapas y momentos conclusivos, desde los cuales es posible percibir la intención y el sentido del proyecto. ¿Cuál era el objeto de este proyecto? Sin duda: destituir al sujeto de la poesía modernista (el de Huidobro, Neruda, De Rokha) de sus funciones utópicas o visionarias. Es decir, destituirlos de la identidad que tales funciones utópicas y visionarias le otorgaban: la de un vocero privilegiado del presente y el futuro de una comunidad (o de un hombre) deseada, y, en tanto deseada, portadora de una promesa de comunidad libre verdaderamente. En otras palabras: se trataba de destituir al sujeto de una identidad utópica o visionaria que para Foucault era la de un intelectual que él llamaba "universal", en oposición a la identidad que los tiempos actuales exigirían: la de un intelectual "específico".

Ahora, hay un aspecto no siempre destacado en la crítica de la antipoesía: si bien el proyecto antipoético de Parra era antimodernista (anti-utópico, anti-visionario), no lo construye desde fuera del modernismo, desde una instancia que lo excluya y lo reduzca a ser, mediado por la distancia, el objeto cuestionado y enfrentado. Por el contrario, la construcción tiene lugar desde el interior del modernismo: empleando fórmulas, gestos modernistas, entre ellos sobre todo el gesto rupturista, que se vuelven sobre sí mismos para ser negados desde un sujeto y un lenguaje que son la caricatura, la distorsión, el sarcasmo, en resumen, la inversión del sujeto y del lenguaje modernistas. El proyecto antipoético, dijimos, avanza por etapas dentro de una lógica dialéctica cuya culminación, o cumplimiento, no podía sino conducirlo al nuevo poema, salvando así su verdad, a su propia inmolación. Los Artefactos representan justamente esa inmolación del "anti". Una inmolación como desintegración tanto del personaje como del lenguaje antipoéticos. A la manera, diría, del modelo cristiano: la verdad del mensaje requiere del sacrificio del mensajero. En este sentido, los dos libros de Sermones y prédicas del Cristo de Elqui representan, según ese modelo cristiano, una suerte de "resurrección" del

6 Michel Foucault, Un diálogo sobre el poder. Traducción de Miguel Morey. Madrid, Alianza Editorial, 1981, pp. 139-141. 
sujeto bajo la forma de un sujeto ya destituido y donde el lenguaje en que se enuncia, como corresponde, exhibe, paralelamente, una identidad puramente fantasmagórica.

Con los Sermones y prédicas del Cristo de Elqui el proyecto antipoético de Parra, el antimodernista, se cierra, es decir, cumple su objetivo y el antipoema agota la misión de sus componentes ${ }^{7}$. El mismo Parra pareciera tener cierta conciencia de ello. En Ecopoemas (un pliego de ocho páginas publicado en 1982, o sea, posterior a los Sermones) hay un poema, el primero, que deja traslucir lo que yo leería como un saber conscientemente irónico acerca de que el ciclo de la verdadera "antipoesía" ha llegado a su término. El poema, "Sonó la antipoesía", dice a renglón seguido: "Ya no es una fuerza creadora / hay que volver a partir de cero / se quedó en lo que era la pobre / en una rebeldía sin causa / la rebeldía + la rebeldía". Hay que "volver a punto cero". Pero el "volver" a punto cero no es sino una manera desplazada de declarar trazado el arco de la verdadera "antipoesía". El "punto cero" remite a un después y no a un antes. Deberá pues el poeta atenerse al presente, a responder de algún modo a las condiciones sociales, culturales, políticas del mundo posmoderno, y al mismo tiempo a las condiciones internas derivadas del hecho de escribir desde una postpoesía antimodernista. Parra responderá con una poesía que, aparentemente, no pierde la memoria de lo que fue, que opera con los mismos medios con que había trabajado (lenguaje cotidiano, personaje antiheroico, humor, ironía, etc.), pero que representa un orden poético perfectamente diferenciado. La memoria de esos medios, su presencia en la nueva poesía, es lo que les permite (pero no legitima) a críticos o simples lectores seguir hablando de "antipoesía" sin más.

La tarea inmediata de estas páginas consistirá, entonces, en hacerse cargo críticamente de esta última poesía de Parra, la "posmoderna". Una tarea asumida aquí, me adelanto a advertirlo, sin ninguna intención de llevarla adelante mediada por un análisis "textual” minucioso, pormenorizado.

7 El último gran poema de Parra, "El hombre imaginario", de 1979, aun cuando está fuera del proyecto, está escrito en su cercanía inmediata y parece todavía compartir su intensidad. 
Consistirá solo en tratar de trazar un conjunto mínimo de líneas de sentido que sean demarcatorias, las más ostensibles como constitutivas de la identidad posmoderna de esta antipoesía. ¿Cómo definirla? Sigue siendo por cierto una poesía de gran audiencia, y, sobre todo en las últimas décadas, de gran manejo mediático. Pero, ¿cuáles podrían ser en esta poesía aquellas marcas que deberían de alguna manera tenerse en cuenta en el momento de su definición? Propongo a continuación algunas de ellas.

La primera, y la más general, no es sino una consecuencia inevitable del cierre del proceso abierto por la antipoesía en su fase antimodernista. Un cierre, dije, practicado con los libros de los Sermones. Ahí, en el interior de ese proceso concluido, la inclusión de los textos de cada libro, y el lugar de cada uno de los libros mismos dentro de su sucesión, estaba sometido a determinada "lógica", de acuerdo con la cual ocupaban un lugar funcional o estratégico. Llegado este proceso (las etapas de su desarrollo) al punto de su desenlace, es decir, al punto de resolución de la lógica que lo gobernaba, los libros que vendrán después no podrían ser sino libros de producción mediada por una profunda inflexión: justamente la inflexión mediante la cual la antipoesía entra en la lógica del posmodernismo poético, artístico, cultural. Me detendré a continuación en dos aspectos de este nuevo y último estado de la antipoesía: en cómo se organizan, o estructuran, los nuevos libros de Parra publicados desde la década de 1980 en adelante, y con qué recursos (de lenguaje) despliegan esos libros su contenido y su forma.

De los numerosos libros publicados por Parra desde la década del 80, una buena parte son antologías. Entre ellas: Poesía política (prólogo de Enrique Lafourcade) ${ }^{8}$, Chistes parradesorientar a la policía poesía (selección y prólogo de Nieves Alonso y G. Triviños -el título es el mismo de un libro anterior de Parra $)^{9}$, Poemas para combatir la calvicie (selección y prólogo de Julio Ortega) ${ }^{10}$, Páginas en blanco (selección de Niall Binns) ${ }^{11}$, How to look better \& fell great (selección de Liz Werner) ${ }^{12}$. Podríamos considerar asimismo como antología (aunque inusual, por cuanto además de los poemas, incluye también textos de un grupo amplio de críticos de la antipoesía) el

Santiago, Editorial Bruguera, 1983.

Madrid, Visor Libros, 1989.

México, Fondo de Cultura Económica, 1993.

Salamanca, Ediciones Universidad de Salamanca, 2001.

New York, New Directions, 2004. Los poemas elegidos son del libro Hojas de

Parra. 
número especial que le dedica a Parra la revista satírica The Clinic $^{13}$. Estas antologías suelen incluir también, unas más, otras menos, poemas inéditos. En cualquier caso, no es en ellas donde habría que encontrar y definir los nuevos criterios de inclusión (y sucesión) que ocuparían el lugar de los que rigieron la etapa anterior de la antipoesía, es decir, los que se dejaban identificar como "estratégicos" y "funcionales". Obviamente, la elección de los textos en las antologías, que pueden pertenecer a libros de distintas épocas, responde, en último término, al criterio estético del autor de la antología.

En cambio sí resultan visibles en aquellos libros de Parra que no son antologías. Quiero empezar, por razones que me acomodan, con uno de estos libros, que no es el primero: Hojas de parra, publicado en $1985^{14}$. Ocurre que el mismo Parra ha comentado posteriormente, en una de sus muchas entrevistas, algunas de las particularidades de este libro que aquí son pertinentes. En efecto, el comentario de Parra introduce, mediado por su forma humorística, precisamente el modo de composición del libro. Hablando de los poemas que lo integran, dice: "fíjate tú, ninguno de estos poemas se hubiera podido publicar junto con los Artefactos, ni tampoco con los del Cristo de Elqui, ¿verdad? No tiene nada que ver con el Cristo de Elqui esto. Entonces eran poemas que iban saliendo, se iban acumulando, y de repente yo vi que los podía juntar. Sin la pretensión de hacer un libro propiamente tal, sino que simplemente esa es una suma. Pero a mí me parece que un libro también se puede hacer así" 15.

Este modo de composición, de "hacer" un libro, preside de alguna manera la composición de sus libros "posmodernos". Ya no estamos pues en la época del libro de campo interiormente delimitado y sometido a una determinada identidad. Ese libro asiste a su muerte simbólica con los Artefactos. Hojas de parra, en efecto, nos sitúa en un campo "abierto". Más que "construido", un campo formado por elementos que simplemente se "juntan", se "suman", en una relación entre sí lejos por tanto de toda "función" y de toda "estrategia" en el sentido de estas palabras referido a la etapa antimodernista. Más aun: un campo cuya composición no excluye el azar.

13 Santiago, 21 de octubre de 2004.

14 Santiago, Ediciones Ganymedes.

15 Leonidas Morales. Conversaciones con Nicanor Parra. $4^{\mathrm{a}}$ ed. Santiago, Ediciones de la Universidad Diego Portales, 2014, p. 110. 
Un libro anterior del período posmoderno, también portador de claves de comprensión crítica con una gran proyección más allá de sí mismo (hablo de las obras posteriores), es de 1983: Chistes parra desorientar a la poticta poesía $^{16}$. Si bien el libro se publica en 1983, el material que recoge corresponde a una muestra del año anterior, en la Galería Época, de cajas con tarjetas postales, por iniciativa de Lily Ganz, responsable de la Galería. La iniciativa se hacía cargo, en términos de una conmemoración, de los diez años transcurridos desde la publicación de los Artefactos (1972). Justamente las nuevas tarjetas postales son similares a las de Artefactos, pero ahora los textos de Parra aparecen ilustrados por un grupo numeroso de artistas chilenos. El "libro" que las reúne nos permite aislar nuevos rasgos de la específica modalidad posmoderna de la antipoesía. Ellos comprometen esta vez no a la_composición de los libros en cuanto reunión de textos como partes suyas, sino a la composición del discurso que atraviesa los textos.

En primer término, si tenemos en cuenta la posición de los Sermones y prédicas dentro de la historia de la antipoesía, o sea, su posición como frontera, de fin de un movimiento e inauguración de otro, el discurso posmoderno, podríamos definir con bastante propiedad la forma en que se nos aparece este último recurriendo a un concepto (no libre de malentendidos, pero útil) introducido por Fredrik Jameson. Pienso en su concepto de "pastiche", aplicable, creo, a la producción posmoderna de Parra (desde la década de 1980 en adelante, dije) vista como un todo. Jameson define el concepto así: es la "imitación de un estilo peculiar o único, idiosincrásico". Si bien el pastiche sigue siendo una parodia, ha perdido por completo la profundidad de su componente crítico. Esta "máscara lingüística" que es el pastiche posmoderno representa en la concepción de Jameson un procedimiento productivo prácticamente universalizado en las prácticas de la literatura y del arte posmodernos ${ }^{17}$. Luego veremos que en el pastiche de Parra la ironía, la parodia y el humor, tan reiterados además de característicos en la fase antimodernista de la antipoesía, derivarán hacia una nueva modalidad y a efectos del todo distintos, pero reconocibles desde algunos paradigmas estéticos posmodernos.

16 Este libro recoge el material de una "exposición" de tarjetas de Parra ilustradas por numerosos artistas chilenos.

17 Fredric Jameson. Teoría de la postmodernidad. Traducción de Celia Montolío y Ramón del Castillo. Madrid, Editorial Trotta, 1996, p. 38. 
Ahora bien, siguiendo la conceptualización de Jameson cabe hacer la pregunta obvia: ¿qué estilo, y de quién, es el que imitaría Parra en esta última fase de su producción? La evidencia indica algo aparentemente paradójico, y para nada usual en la literatura y el arte actuales ${ }^{18}$ : que Parra se imita a si mismo. Imita los signos y las estructuras de su fase antimodernista. Y no solo eso: desarrolla de manera radical líneas de creación cuyo modelo originario ya estaba claramente presente en la fase anterior. Hablo en este caso del desarrollo de lo visual. Me referiré a continuación a la formas imitadas, en el mismo orden en que las he enunciado: signos, estructuras, visualidad.

A nivel de los signos, asistimos a la renovada apelación al recurso de intervenir el código de la lengua con signos que pertenecen a otro código. Al código de las matemáticas pertenecen los signos “+”, “x”, “-”, “ \%”: "Lo importante es la canción / o sea la causa / amigo valiente / lo de + es lo de -", "Compañero peatón: / haga patria: / mate un chofer al día / antes que los choferes lo maten a Ud. / el 90 \% del monóxido de carbono / que va a dar a nuestros pulmones / es exhalado x estos murciélagos" (en Chistes parra desorientar a la poticía poesía). Vuelve también un signo del lenguaje del marketing: "\&": "Obras completas \& algo más" (en el título de los dos tomos de sus Obras completas), "Lear Rey \& Mendigo" (título del libro homónimo). Otro signo no verbal que encontramos corresponde al símbolo cristiano de la cruz: el título del poema "Los 4 sonetos del Apocalipsis" no va seguido de ninguna palabra: el lugar de las palabras de los catorce endecasílabos de cada uno de los sonetos lo ocupa el signo de la cruz. Pero lo que importa no es solo constatar la repetición de estos signos interventores, sino comprobar que el efecto provocador o deconstructivo que ellos produjeron en el período anterior se ha perdido. Asumimos su lectura como un simple déjà vu.

La imitación posmoderna que practica Parra de sí mismo se extiende también, de manera por lo demás manifiesta, más allá de los signos aislados, para comprometer el plano del discurso, y en él, a determinadas estructuras de lenguaje poético. La más evidente es la estructura misma de los Artefactos de 1972. Recordemos brevemente sus componentes principales. Se trata de textos formados por un pequeño número de "versos" (dos, tres, cuatro líneas). Los versos entre sí establecen relaciones de muy diversa clase, sobre todo de humor, de ironía, de contradicción estratégica local, con un énfasis

18 En Borges hay ciertos juegos en este sentido, pero dentro de un orden estético no comparable. 
crítico de mayor o menor intensidad. A veces, el conjunto va encabezado por una palabra o frase a manera de título, y entonces entre el título y los versos se produce un juego de relaciones similares a las ya mencionadas. Estas mismas relaciones se repiten entre el texto y la imagen visual que suele acompañarlo. No olvidemos que los Artefactos se publicaron como cajas de cartón, cuyo contenido era una larga serie de tarjetas postales en su formato tradicional. En el anverso, el texto de Parra lleva, en la mayoría de los casos, una ilustración del texto (un dibujo, una fotografía publicitaria) a cargo del ilustrador Guillermo Tejeda. Ejemplo: "USA / donde la libertad / es una estatua", y al fondo, un dibujo de la Estatua de la Libertad, sonriendo. En el reverso de la tarjeta, arriba, la inscripción "Tarjeta Postal. Post Card", y al centro, en línea vertical, el nombre de la Editorial. El reverso se completa con un listado, a la izquierda y abajo, de sinónimos de la palabra "artefactos" en inglés, francés y alemán, listado que remata con la indicación de autoría, pero en inglés: "C by Nicanor Parra".

El libro posmoderno de Parra donde encontramos una imitación sistemática de los Artefactos de 1972, es Chistes parra desorientar a la policta poesia, 1983. También aquí, en vez del libro, cajas, y en lugar de páginas, tarjetas postales. A la reiteración del formato de la tarjeta postal se suma, también en un número importante de casos, la reiteración del texto ilustrado. Ejemplo: "llore si le parece / yo x mi parte / me muero de risa". Detrás de las palabras, una fotografía de Parra riéndose" (foto de Inés Paulino). En este libro la ilustración estuvo a cargo, como dijimos antes, de un grupo amplio de destacados y conocidos artistas chilenos. Lo que no se repite (no podía repetirse) es el impacto en el lector del artefacto original. Un impacto éste a todas luces subversivo en la medida en que interroga y cuestiona la conciencia del lector, sus expectativas, el sentido ya congelado de su imagen del mundo, de las cosas. Un "pinchazo a la médula", como dirá el propio Parra en una entrevista. Así explica el "pinchazo" en esa entrevista: "Esta noción de pinchazo a la médula es interesante. Se trata de tocar puntos sensibles del lector con la punta de una aguja, de galvanizarlo de manera que el lector mueva un pie, mueva un dedo o gire la cabeza. Interesa mucho no perder de vista la relación de texto a objeto o a mundo que está más allá del texto mismo. El artefacto está apuntando a una realidad que existe con anterioridad al artefacto" 19 . 
De aquella rebeldía cuestionadora, descontructiva, propia del lenguaje y la imagen visual de los artefactos de 1972, de su explosivo componente crítico, solo queda, en el espejo de la imitación, una pálida capacidad de "mover" al lector, una referencia menos crítica a esa "realidad que existe con anterioridad" al poema, justamente por el saber previo del lector sobre el procedimiento discursivo puesto en juego ${ }^{20}$. Incluso, hasta podríamos conjeturar en el autor una cierta conciencia, burlona por supuesto, de la diferencia entre una y otra forma, entre un estado y otro de la misma estructura, cuando, en el título del libro de 1983, anuncia sus poemas no como "artefactos" sino como "chistes". Y no sin razón: más que la ironía crítica, pareciera predominar el humor.

Hasta aquí el foco ha sido puesto principalmente en el plano del lenguaje de la poesía posmoderna de Parra. Si bien me he limitado a reconocer y mostrar en él determinados signos y estructuras discursivas ya operantes en su poesía antimodernista, a emitir algunos juicios críticos de valor sobre los efectos estéticos en el lector de esta imitación de sí mismo, creo sin embargo posible, aunque tentativamente, extraer una primera conclusión (casi a título de hipótesis que requeriría sin duda ampliar su base analítica de sustentación). La siguiente: la poesía posmoderna de Parra a todas luces ha perdido una virtud a la que estuvo siempre asociada su poesía antimodernista: ha dejado de ser ya una poesía subversiva. Esta conclusión solidariza de manera manifiesta con nuestra tesis del pastiche, tal como se configura en Parra. Pero no se piense que si tiene validez, ella se circunscriba al orden estricto del lenguaje poético de Parra, a sus signos y estructuras discursivas. Por el contrario, la pérdida señalada hay que hacerla extensiva asimismo a ese otro plano con el que de pronto la palabra de Parra entra en juego, y que en la fase posmoderna adquiere cada vez más desarrollo: me refiero al plano de lo visual, un plano que incluso experimentará internamente, como luego diré, una suerte de metamorfosis. Que la pérdida sea compartida es por lo demás

20 Tampoco la imitación de 1983 podía recrear y continuar, por razones de lógica histórica elemental, el simbolismo de los Artefactos dentro del proceso de la antipoesía en su fase modernista. 
inevitable: cuando lo visual aparece en el campo del poema, forma con las palabras una sola estructura. Son pues planos interdependientes.

Los Artefactos de 1972 son, en este sentido, un punto de partida. Representan, dijimos, dentro del proceso del que forman parte, el "fin" del libro como soporte clásico de la poesía. Agreguemos aquí: representan el fin simbólico de los privilegios de la palabra. La palabra, en ellos, comparte su espacio con lo visual, quiero decir, con la imagen visual. ¿Cuál ha sido el destino de la imagen visual en la poesía posmoderna de Parra? Desde el punto de vista de su reiterada presencia y de cómo cada vez se vuelve más protagónica, su destino final ha sido sin duda "rutilante". Pero no ha sido sin pagar costos. Por lo pronto cabe decir que lo visual ha dejado atrás la época de las trincheras, y ha terminado al servicio, casi complaciente a ratos, por lo menos relajado, de los dioses perversos de la mercancía y su publicidad. Los mismos, como ha mostrado Baudrillard tantas veces, que han vaciado a la imagen posmoderna (en pintura, en literatura) de su trasfondo de sentido, de su profundidad, convirtiéndola en la protagonista porno de sus estrategias de seducción ${ }^{21}$.

En los Chistes parra desorientar a la policía poesía la imagen visual funcionaba como una "ilustración" del texto. Es decir, dentro de sus relaciones significantes de dependencia mutua, el texto seguía ocupando una cierta posición de preeminencia. La imagen ilustraba al texto, lo leía y lo traducía en términos de visualidad. Poco a poco, en las producciones siguientes de Parra, texto y dibujo experimentarán tres grandes transformaciones. Una: abandonan el espacio impreso de la tarjeta postal. Dos: el dibujo es reemplazado por un objeto de la realidad exterior, del mundo cotidiano: una mamadera, un huevo, unas planchas antiguas, etc. Tres: del espacio impreso de la tarjeta postal pasan necesariamente al espacio público de las exposiciones de arte. El texto reduce su extensión y adopta una forma similar a la del título de un cuadro, de una pintura: una palabra, una frase de mayor o menor extensión. Ejemplos: Un Cristo de yeso en la cruz con una pierna mutilada, y abajo: "Sin comentario". Otro Cristo en una cruz artesanal, hecha de junco, y abajo: "El que pierde gana". Una vieja máquina de escribir Underwood, y abajo: "La máquina del tiempo". Tres calaveras, una al lado de la otra, y abajo: "Las 3 calaveras de Colón". Un tomo rojo de "Obras escogidas" de Marx y Engels,

21 Ver en Jean Baudrillard, por ejemplo, La ilusión y la desilusión estéticas. Traducción de Julieta Fombona. Caracas, Monte Ávila Editores, 1997. 
y abajo: "Los rollos del Marx Muerto", con la x de Marx reemplazada por la cruz gamada del nazismo.

Las relaciones de preeminencia interna aquí se invierten: el objeto visual se impone en un plano de exposición mayor, mientras el texto reduce su extensión y acaba siendo una "ilustración" verbal irónica o cómica de la imagen visual. De todos modos el juego significante entre ambos planos se mantiene. El procedimiento de inversión de inmediato evoca su origen: su genealogía conduce evidentemente a Duchamp. La renuncia total de la poesía y del arte a sus viejas autonomías, que eran las autonomías de sus reductos imaginarios, y su apertura a la materialidad de los objetos de la realidad cotidiana, del mundo exterior (donde la palabra es uno más de ellos), y a la producción artística de otras relaciones significantes. Así fue sucediendo en la producción posmoderna de Parra desde temprano. El producto de las nuevas prácticas artísticas fue ordenándose en conjuntos que se exponían al público con nombres diversos: "Ejercicios prácticos", "Artefactos visuales", "Obras públicas".

Estas exposiciones ${ }^{22}$, con sus respectivos curadores y catálogos, comenzaron en Valencia, en 1992, con una exposición conjunta de Parra y el poeta visual catalán Joan Brossa, bajo el título de "Dir poesía / Mirar poesía". La muestra de Parra estuvo formada por 13 "Artefactos visuales" (en el catálogo lleva como subtítulo "Obras públicas"). La exposición se repitió a fines del mismo año en Chicago. Desde entonces ${ }^{23}$, vinieron otras "exposiciones". Reuniendo una colección de más de 200 piezas, el 2001 la Fundación Telefónica presentó, primero en España (Madrid) y luego en Chile (Santiago), la exposición "Trabajos prácticos y artefactos visuales". En el catálogo correspondiente se introduce en el título una variante: "Trabajos prácticos: Dirección obligada". Al año siguiente, la exposición se repitió, con el título del catálogo, en Concepción. Por último, el 2006, se presentó, en el Centro Cultural Palacio La Moneda (CCPLM), con el título de "Obras públicas. Ver para creer", una nueva exposición. De todas, ésta ha sido la más totalizadora del trabajo visual de Parra.

22 La información sobre las exposiciones de Parra la aportan los editores del segundo tomo de las Obras completas, obra citada, pp. 1119-1138.

23 En 1996, Ediciones CESOC publica, en Santiago, el libro Hojas de Parra que, a diferencia de la edición original, aparece dividida en dos partes. El título de la segunda parte (editada como reverso de la primera) es "Trabajos prácticos". Las fotografías de la muestra son de Paz Errázuriz. 
No cabe duda, los "artefactos visuales" llaman la atención del espectador (lector en catálogos y libros), y hasta pueden de alguna manera seducirlo, sobre todo al espectador más masivo, de cultura más general, en la medida en que éste sin dificultad decodifica su sentido inmediato y se siente así "incorporado" por ellos al mundo del arte. Pero la imagen visual de estos artefactos no pertenece a la clase de imagen de la que se ocupa Didi-Huberman, es decir, no pertenece al mundo de aquellos objetos de arte visual (fotografías, esculturas, dibujos, pintura, etc.) que "nos miran" cuando "los vemos": nos "miran" desde el horizonte de sentido que la imagen que "vemos" nos abre, nos hace "aparecer" (a la manera de una imagen "dialéctica", de una imagen "aurática"). Lo que nos "mira" desde su horizonte introduce en el sujeto, en el mundo del espectador, una fisura. Una fisura que no está exactamente en lo que "vemos" sino que nos "mira" desde "otra parte"

Por lo pronto, la imagen visual posmoderna de Parra está muy lejos de apelar a su espectador del modo en que lo hacía la de los artefactos de 1972, donde sí la imagen que vemos nos abre a una fisura que nos "mira". En otras palabras: su nueva imagen visual ya no está en condiciones de reproducir el efecto crítico de la imagen de aquellos artefactos primeros. Por el contrario, se ha vuelto una imagen "consumible" por su espectador. Más exactamente: se ha transformado en gran medida en una imagen visual como "espectáculo", en términos de Débord ${ }^{25}$. Un episodio sencillo tomado de los medios de comunicación ilustra de manera irrefutable este paso de la imagen crítica a la imagen sin fisura de lo consumible. El canal de televisión chileno 24 Horas, en un reportaje desde Italia sobre el stand chileno en la Exposición Internacional de Milán 2015, entrevista al mediático chef Carlo von Mühlenbrock ${ }^{26}$. El "punctum" (Barthes) de la escena no está en lo que dice el chef sino en la polera que viste. En ella aparece estampada una conocida figura de los artefactos visuales: el dibujo, del propio Parra, de un corazón con ojos, brazos y piernas, trazados solo con líneas a la manera de los dibujos infantiles. Cambia la mirada y la posición de piernas y brazos

24 Georges Didi-Huberman, "Lo que vemos, lo que nos mira". Traducción de Horacio Pons. Buenos Aires, Ediciones Manantial, 1997. Las citas son del capítulo dos, "La evitación del vacío: creencia o tautología", pp. 19-26.

25 Guy Débord, La sociedad del espectáculo. Hay varias ediciones en español. Una de ellas: la traducción chilena de Rodrigo Vicuña Navarro, Santiago, Ediciones Naufragio, 1995.

26 Viernes 22 de mayo, 10,48 hrs. 
según el sentido del texto que va con él. Así pues, una imagen visual de la que sintomáticamente se ha apropiado, como tantas otras, el mercado de la sociedad de consumo.

Por último, en el pastiche de la poesía posmoderna de Parra hay otro caso de imitación de sí mismo igualmente relevante. De nuevo debo remitir a los Artefactos de 1972. Junto con asistir en ellos a la presencia recurrente de la imagen visual, observábamos también que el texto de muchos de estos artefactos no estaba impreso sino caligrafiado. Era la escritura caligráfica del mismo Parra. En un libro donde todo estalla, empezando por el libro mismo, la caligrafía se suma a los recursos con los cuales Parra pulveriza la noción modernista de escritura poética. En efecto, la letra caligráfica permite destituir la letra impresa de su lugar de privilegio en la comunicación poética. Lo hace porque, como toda artesanía, la letra caligráfica es un producto del cuerpo, singular, irrepetible, y por lo tanto incompatible con la letra impresa, un producto serial. De manera entonces que la letra caligráfica cumplía, por sí misma, una función abiertamente provocadora, disruptiva.

No hay que pasar por alto en todo caso una conexión significativa. En el contexto de la antipoesía, la letra caligráfica es algo más que un producto del cuerpo: es una metonimia del cuerpo como cuerpo de un sujeto biográfico: Parra. El sujeto biográfico Nicanor Parra irrumpe, pues, con su caligrafía metonímica, desafiando una concepción de escritura como la sostenida por Foucault: una escritura donde "no hay manifestación o exaltación del gesto de escribir; no se trata de la sujeción (épinglage) de un sujeto en un lenguaje; se trata de la apertura de un espacio en el que el sujeto que escribe no deja de desaparecer" ${ }^{27}$. Los Artefactos cuestionan así (de nuevo, en la herencia de Duchamp), junto con la idea de libro, la noción de autor como aquel que en su escritura "no deja de desaparecer". Al revés, en ellos el sujeto que escribe no deja de "aparecer".

Este juego con la caligrafía metonímica continúa en la fase posmoderna de la antipoesía, por ejemplo, en Chistes parra desorientar a la policía poesía. Pero aquí el juego pierde su fuerza explosiva para transformarse en un mero dispositivo visual reiterativo, imitación de sí mismo. Incluso en algunos de estos artefactos devenidos en "chistes", la metonimia de la letra caligráfica se vuelve "tautológica": en el mismo espacio visual que la contiene, compartiendo

27 Michel Foucault, “¿Qué es un autor?”. Obras esenciales, Volumen I. Traducción de Miguel Morey. Barcelona, Ediciones Paidós, 1999, p. 333. 
este espacio, nos encontramos con una fotografía del propio Parra. Estos artefactos visuales, además de ser un simulacro de sabotaje de la distancia entre autor y sujeto biográfico, y de ponerse claramente en la cadena nutricia de la imagen visual "consumida", despliegan un fenómeno narcisista solo en estado germinal en la fase antimodernista. En la posmoderna, en cambio, llega a ser casi invasiva bajo la forma de recitales donde el autor es una "star", de series fotográficas, de "exposiciones" que al mismo tiempo lo "exponen". El proceso de la visualidad se completa con el autor convertido en su propio "espectáculo" como sujeto biográfico.

\section{BIBLIOGRAFÍA}

Baudrillard, Jean. La ilusión y la desilusión estéticas. Traducción de Julieta Fombona. Caracas: Monte Ávila Editores, 1997.

Débord, Guy. La sociedad del espectáculo. Traducción de Rodrigo Vicuña Navarro, Santiago: Ediciones Naufragio, 1995.

Didi-Huberman, Georges. Lo que vemos, lo que nos mira. Traducción de Horacio Pons.

Buenos Aires: Ediciones Manantial, 1997. Las citas son del capítulo dos, "La evitación del vacío: creencia o tautología”. 19-26.

Foucault, Michel. Un diálogo sobre el poder. Traducción de Miguel Morey. Madrid: Alianza Editorial, 1981. 139-141.

“¿Qué es un autor?” Obras esenciales, Volumen I. Traducción de Miguel Morey.

Barcelona: Ediciones Paidós, 1999. 333.

Jameson, Fredric, Teoría de la postmodernidad. Traducción de Celia Montolío y Ramón del Castillo. Madrid: Editorial Trotta, 1996. 38.

Morales, Leonidas, Conversaciones con Nicanor Parra. $4^{\mathrm{a}}$ ed. Santiago: Ediciones de la Universidad Diego Portales, 2014. 110.

"Nicanor Parra: el proyecto antipoético". Anales de Literatura Chilena. Año 13, $\mathrm{N}^{\mathrm{o}} 17$, junio 2012. 147-167.

Parra, Nicanor. Obras completas \& algo + (1935-1972). Barcelona: Galaxia Gutenberg Círculo de Lectores, 2006. Vol. II.

Obras completas \& algo + (1975-2006). Barcelona: Galaxia Gutenberg Círculo de Lectores, 2011.

Sermones y prédicas del Cristo de Elqui. Santiago: Galería Época, 1977.

Nuevos sermones y prédicas del Cristo de Elqui (1977 y 1979). Valparaíso:

Ediciones Ganymedes, 1979. 